\title{
Protecting and rehabilitating the archaeology of Bethlehem
}

\author{
Lorenzo Nigro ${ }^{1, *}$, Daria Montanari ${ }^{1}$, Mohammed Ghayyada ${ }^{2} \&$ \\ Jehad Yasine ${ }^{2}$
}

Rescue excavations in Bethlehem undertaken by the Sapienza University of Rome and the Palestinian Ministry of Tourism and Antiquities-Department of Archaeology and Cultural Heritage - have revealed four Bronze Age necropolises. These newly discovered sites illuminate the development of pre-Classical Bethlehem.

Keywords: Palestine, Bethlehem, Bronze Age, necropolis

A survey of the city of Bethlehem and its surroundings, implemented as part of the 20152016 Sapienza-Palestinian MOTA-DACH Expedition archaeological investigations, has identified and documented archaeological, historical and cultural sites and monuments dating from the Early Bronze Age to the Islamic Period (fourth millennium BC to second millennium AD) (Figure 1).

Four different necropolises—Khalet al-Jam'a, Jebel Dhaher, Bardhaa and el-Atan-are located on the terraced slopes of the limestone hill of Bethlehem, within a $1.5 \mathrm{~km}$ radius of the Church of the Nativity, and were the subject of rescue excavations in 2015 and 2016 (Nigro et al. 2015, 2017a \& b). Although affected by destruction and looting prior to the MOTA$\mathrm{DACH}$ rescue excavation, the Khalet al-Jam'a necropolis (Figure 2) originally contained at least 100 shaft tombs, which were used during the EB IV (2300-2000 BC) to MB I-III (2000-1500 BC) periods, and up to the Iron Age IB-II (1050-700 BC). Khalet al-Jam'a long use-life and its huge number of tombs and their assemblages (Figure 3) suggest that it was the main necropolis serving the pre-Classical town of Bethlehem from the Middle Bronze Age to the Iron Age (Nigro 2015).

The Jebel Dhaher necropolis (Figure 4) was discovered in 2016 to the south-west of Bethlehem during construction works. It also contained shaft-tombs with round shafts and usually a single, circular, domed chamber. Associated artefacts date the tombs to the EB IVB (2200-2000 BC) to the Middle Bronze Age, with re-use during the Early Iron Age. The Jebel Dhaher and Khalet al-Jam'a necropolises were therefore contemporaneous.

1 Department of Oriental Studies, Sapienza University of Rome, Piazzale Aldo Moro, 5-00185 Rome, Italy

2 Department of Antiquities and Cultural Heritage, Ministry of Tourism and Antiquities of Palestine, P.O. Box 870 Ramallah, West Bank, Palestine

* Author for correspondence (Email: lorenzo.nigro@uniroma1.it)

(C) Antiquity Publications Ltd, 2018 ANTIQUITY 92 365, e5 (2018): 1-7 

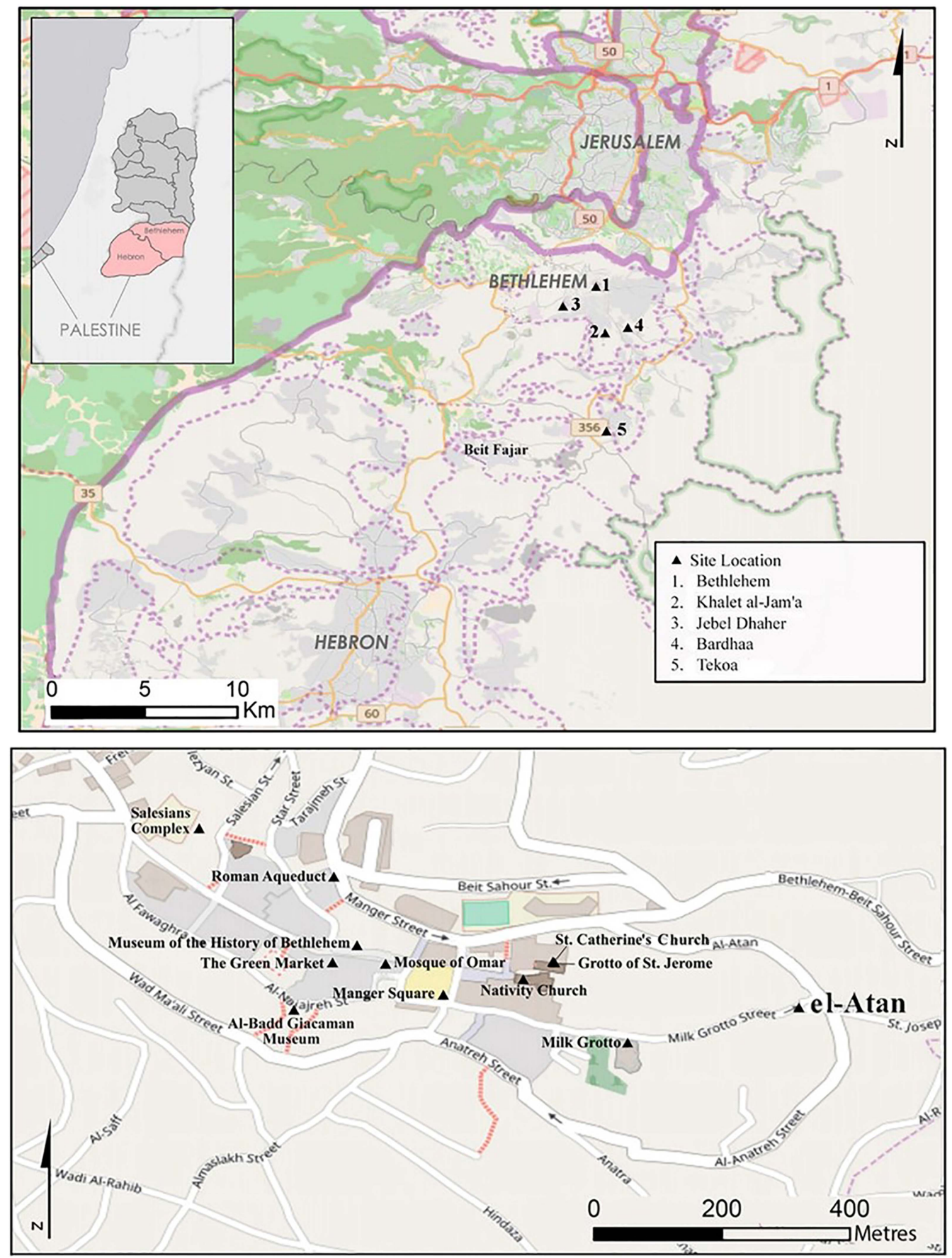

Figure 1. Top) map of the area of Bethlehem with necropolis locations; bottom) city centre with el-Atan tomb location.

(C) Antiquity Publications Ltd, 2018 


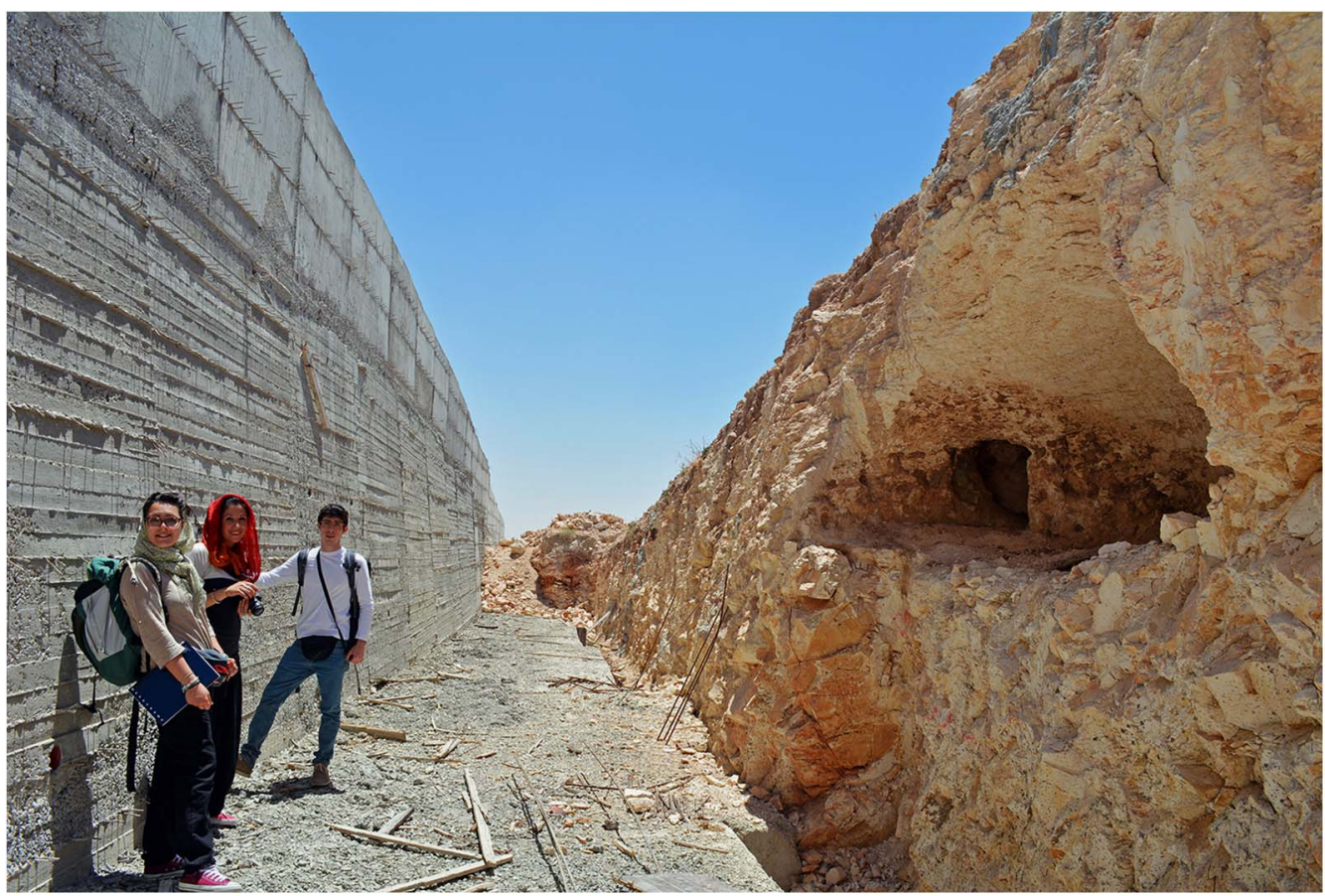

Figure 2. Khalet al-Jam'a tomb 9 during rescue excavation in 2015, looking south.

To the east of Khalet al-Jam'a lies a necropolis (Bardhaa) in the village of Bardhaa (Figure 5), which was looted between 1967 and 1995. MOTA-DACH estimates that there were originally around 50 tombs. Excavations at Bardhaa revealed that the tombs are mostly of the shaft-single chambered type, with squared or round shafts. Bardhaa began use in the EB IV period and flourished in the Middle Bronze Age. As with Khalet al-Jam'a and Jebel Dhaher, the Bardhaa necropolis belongs to a system of cemeteries first established in the Early Bronze Age, between Wadiat 'Artas, Wadi Ta'amireh and Wadi et-Tin to the south of Bethlehem up to Tekoa. The necropolises were possibly connected to local late thirdmillennium BC sister tribes.

An EB IVB tomb (el-Atan) was discovered accidentally in 2009 close to the Milk Grotto, in el-Atan Street, Bethlehem. This shaft single-chamber tomb was part of the Early Bronze Age to Byzantine-period cemetery extending to the east and south of the Church of the Nativity (Prag 2000: 177). In 2016, the MOTA-DACH, with the help of Sapienza, examined human remains and a composite ceramic assemblage dating to the EB IVB from that tomb (Figure 6). 

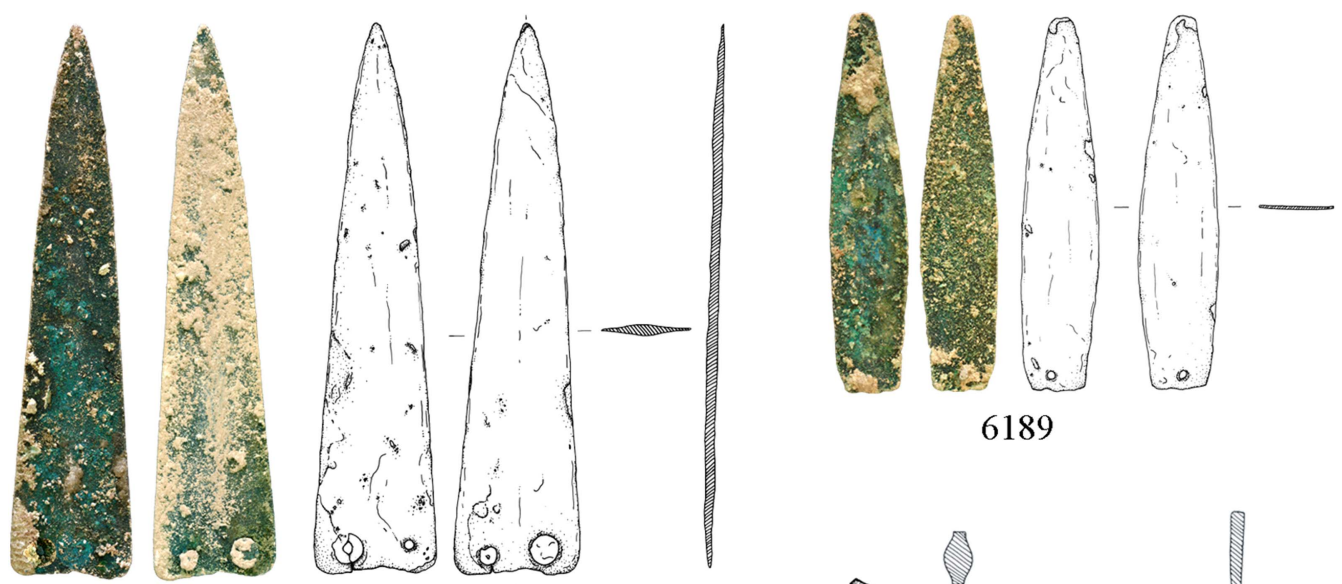

\section{7}
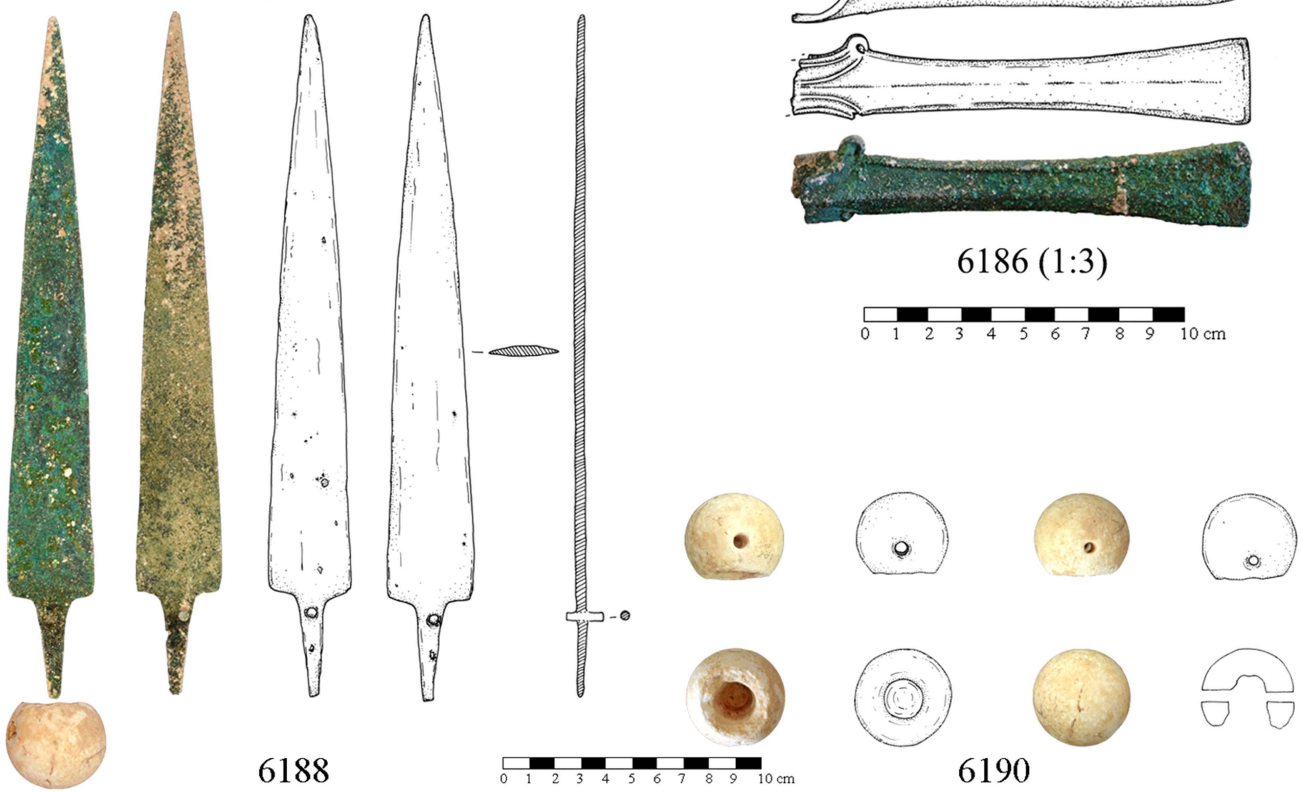

6188

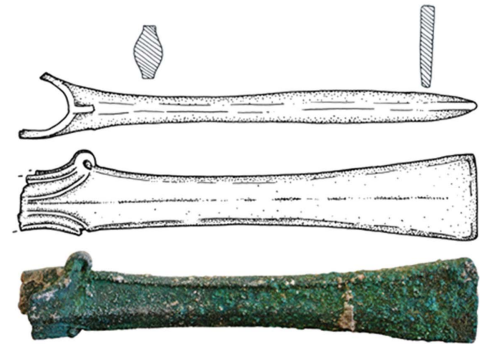

$6186(1: 3)$
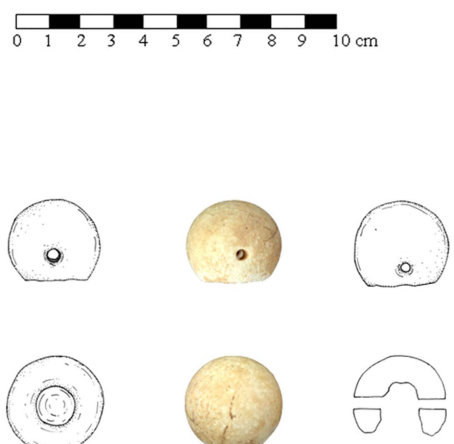

6190

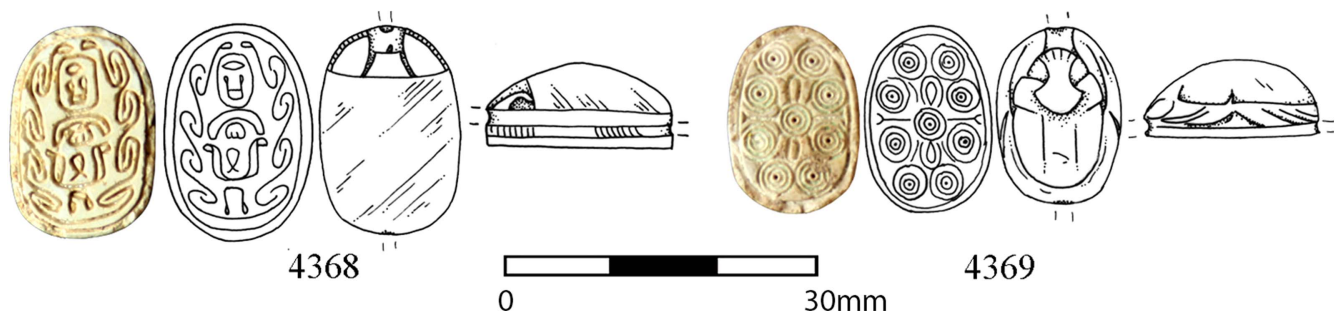

Figure 3. Weapons and scarabs from Khalet al-Jam'a tomb A2.

(C) Antiquity Publications Ltd, 2018 


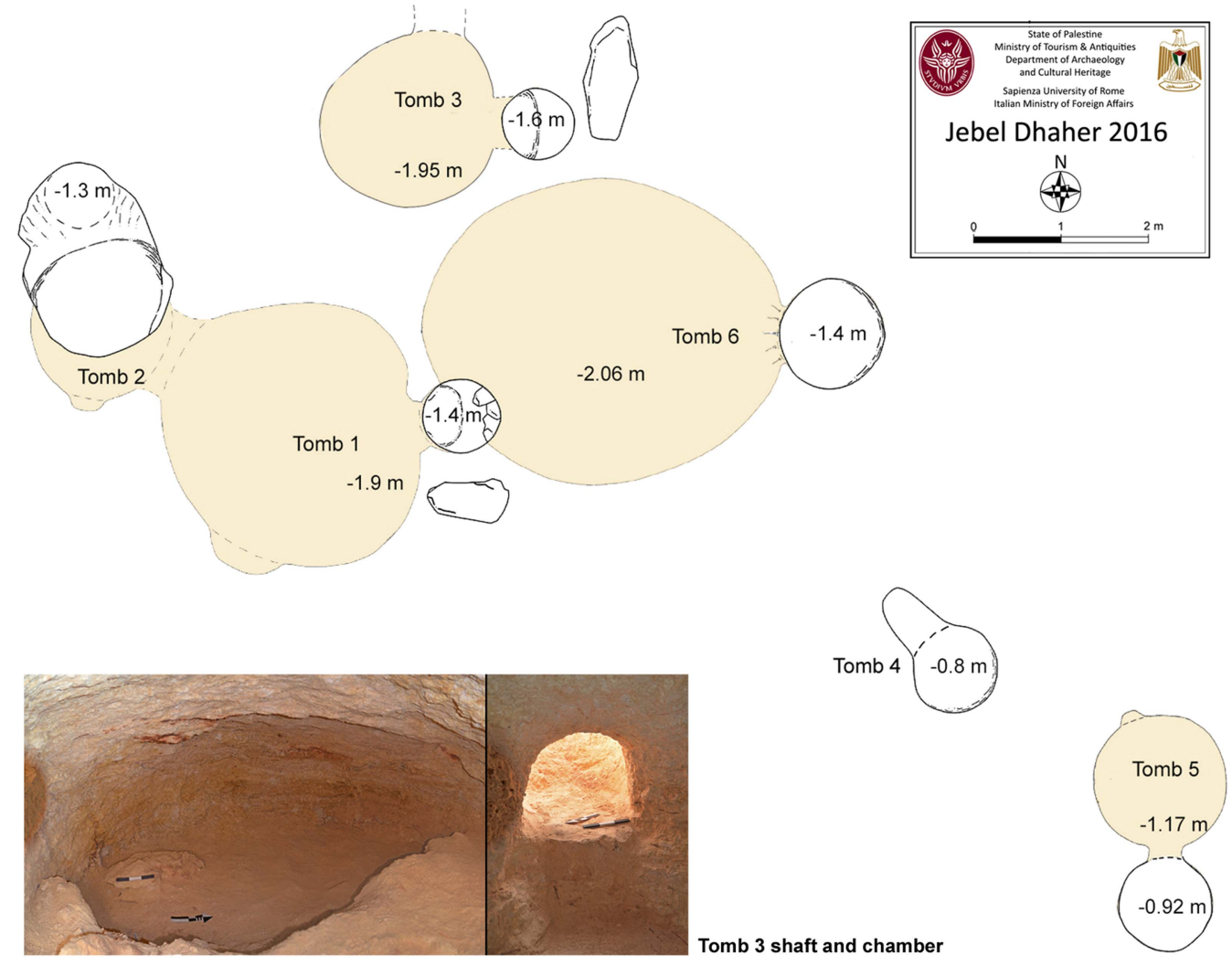

Figure 4. Map of four tombs in the Jebel Dhaher cemetery (2016).

The newly discovered Early and Middle Bronze Age cemeteries of Khalet al-Jam'a, Jebel Dhaher, Bardhaa and el-Atan illuminate the history of Bethlehem in the third and second millennia BC. The lack of pre-Classical documentary evidence (a disputed mention in the el-Amarna Letters is no longer considered reliable) forces a reliance on archaeological data as a means to understand settlement and occupation patterns. Cemetery clustering from the Early Bronze Age onwards suggests that, as with Jerusalem, Bethlehem gradually developed into a fortified town, culminating in the Middle Bronze Age with the rise of a city. The EB IV necropolises, which were used throughout the Middle and Late Bronze Ages, and, in the cases of Khalet al-Jam'a and Jebel Dhaher, into the Iron Age, provide strong evidence for 


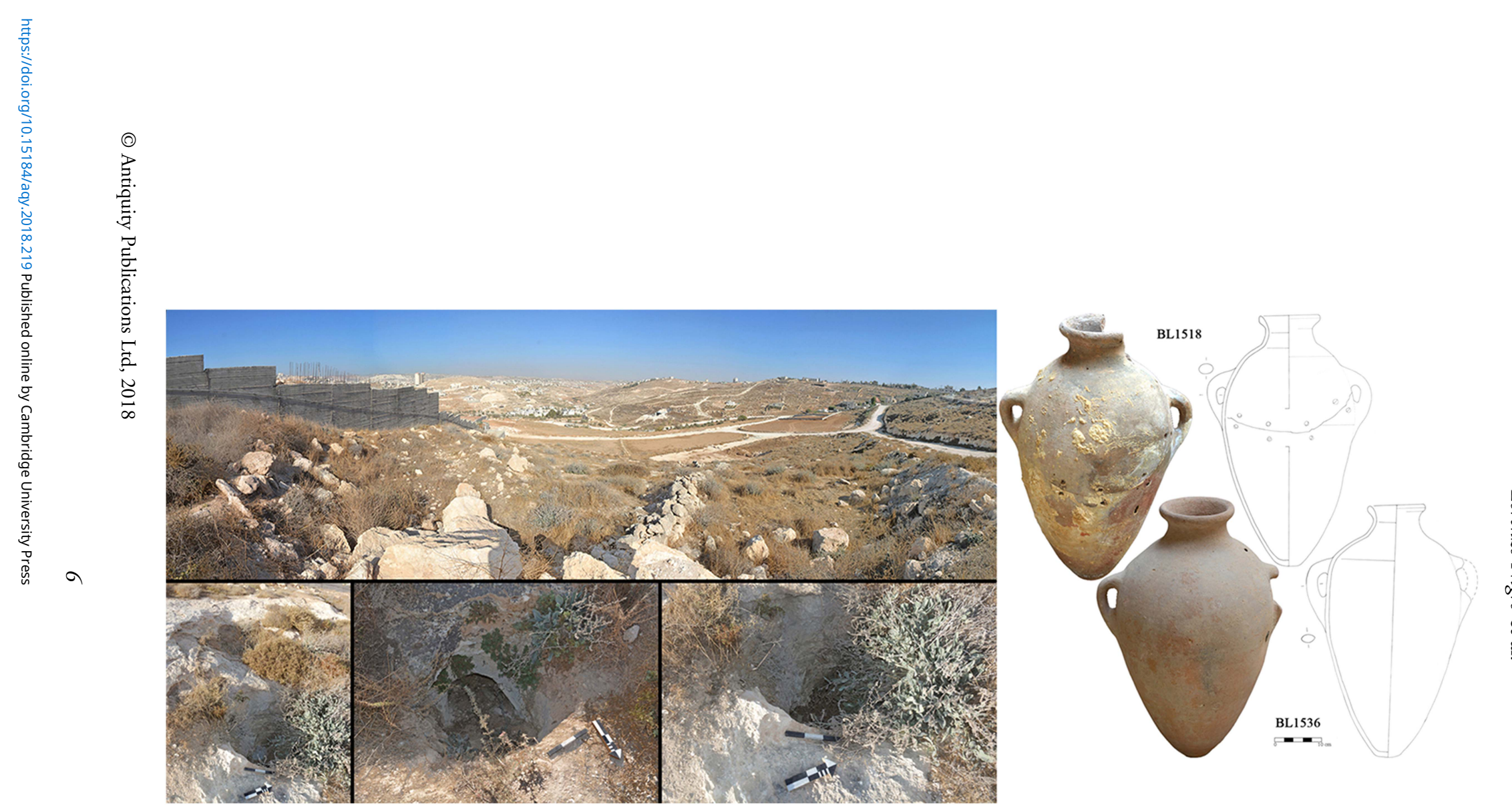

Figure 5. Bardhaa necropolis: panoramic view from the north and details of three shafts (left); two Middle Bronze Age jars (right). 


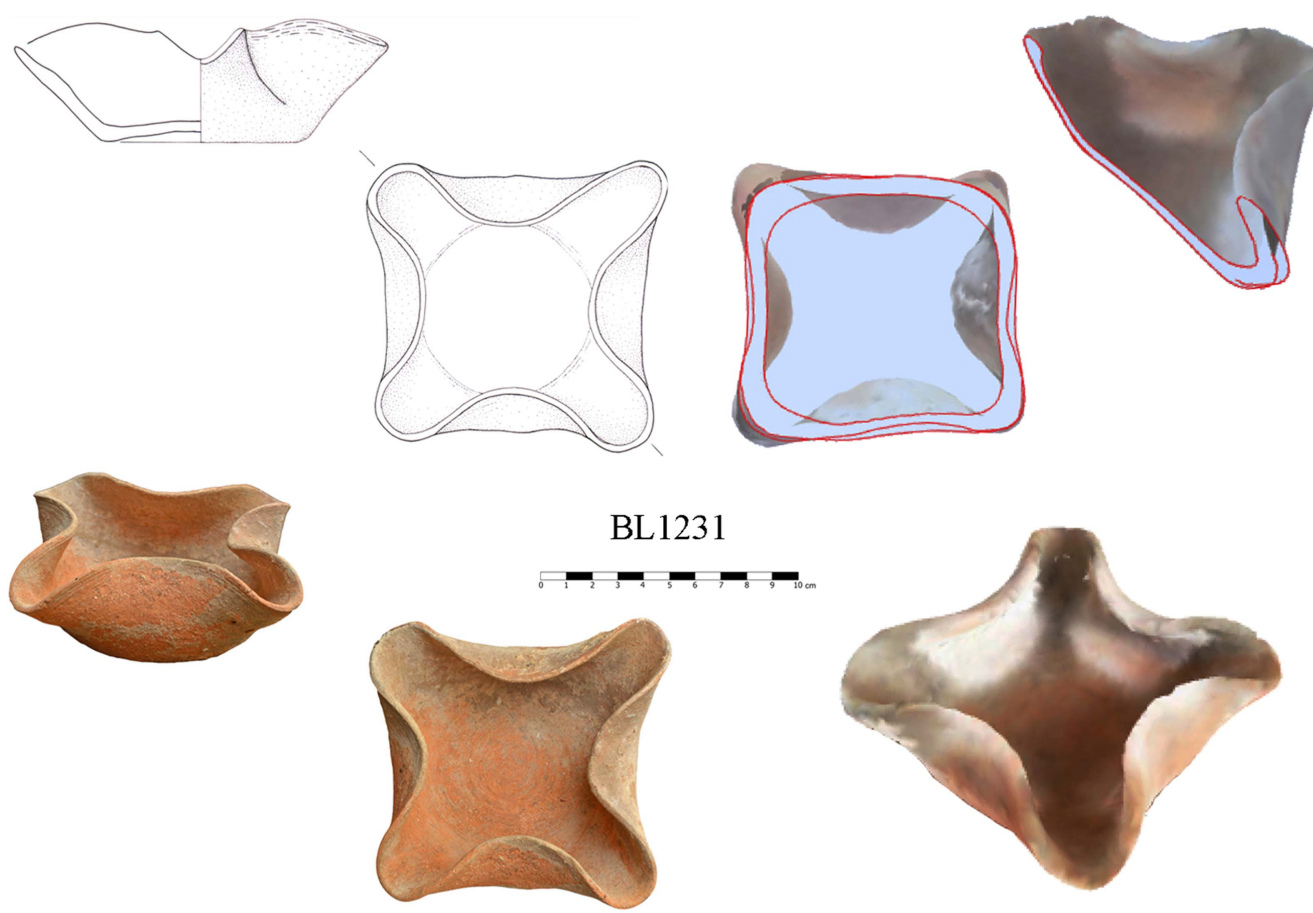

Figure 6. An EB IVB four-spouted lamp from el-Atan Tomb, with 3D sections and rendering (right).

progressive sedentism and the rise of a city that controlled trade and transhumance by nomadic and semi-nomadic tribes living in the wadis west of the Dead Sea.

\section{Acknowledgements}

Work at Bethlehem is carried out in cooperation with the Ministry of Tourism and Antiquities of Palestine. Our deepest thanks go to Rula Maa'yaa and Saleh Tawafsha. Special thanks are given to the Italian Ministry of Foreign Affairs and International Cooperation, the DGSP_Ufficio VI Settore Archeologia and the Italian Consulate in Jerusalem. Our thanks also go to the Academic Authorities of Sapienza University of Rome, E. Gaudio, Stefano Asperti, Teodoro Valente, Bruno Botta, Alessandra Brezzi and Claudio Lombardi for their academic and technical support, and to all these institutions that made the present study possible. All figures are copyright of the Sapienza University of Rome Expedition to Palestine and Jordan.

\section{References}

Nigro, L. 2015. Bethlehem in the Bronze and Iron Age. A summary in the light of recent discoveries by the Palestinian MOTA-DACH. Vicino Oriente XIX: $1-15$.

Nigro, L., D. Montanari, M. Ghayyada \& J. Yasine. 2015. Khalet al-Jam'a. A Middle Bronze and Iron Age necropolis near Bethlehem (Palestine). Vicino Oriente XIX: 185-218.
- 2017a. The el-Atan tomb: an Early Bronze IVB female burial in the heart of Bethlehem. Vicino Oriente XXI: 225-56.

Nigro, L., D. Montanari, A. Guari, M. Tamburrini, P. Izzo, M. Ghayyada, I. Titi \& J. YASINE. 2017b. New archaeological features in Bethlehem (Palestine): the Italian-Palestinian rescue season of 2016. Vicino Oriente XXI: 5-57.

PraG, K. 2000. Bethlehem: a site assessment. Palestine Exploration Quarterly 132: 169-81. https://doi.org/10.1179/peq.2000.132.2.169 